OPEN ACCESS

Edited by:

Andreas Dietz

Leipzig University, Germany

Reviewed by:

Giuseppe Mercante

Regina Elena National Cancer Institute

(IRE), Italy

Chandra Shekhar Dravid,

Tata Memorial Hospital, India

*Correspondence:

Erika Crosetti

erika.crosetti@ircc.it

Specialty section

This article was submitted to

Head and Neck Cancer,

a section of the journal

Frontiers in Oncology

Received: 13 January 2019

Accepted: 30 April 2019

Published: 22 May 2019

Citation:

Succo G and Crosetti E (2019)

Limitations and Opportunities in Open

Laryngeal Organ Preservation

Surgery: Current Role of OPHLs.

Front. Oncol. 9:408.

doi: $10.3389 /$ fonc. 2019.00408

\section{Limitations and Opportunities in Open Laryngeal Organ Preservation Surgery: Current Role of OPHLs}

\author{
Giovanni Succo ${ }^{1,2}$ and Erika Crosetti ${ }^{2 *}$ \\ ${ }^{1}$ Oncology Department, University of Turin, Turin, Italy, ${ }^{2} \mathrm{Head}$ Neck Oncology Unit, Candiolo Cancer Institute, FPO IRCCS, \\ Turin, Italy
}

The current trend for treatment of intermediate-early advanced laryngeal cancer is essentially oriented toward preservation of organ and laryngeal function, and with a good potential for treating the disease. This goal can be achieved by adopting open laryngeal organ preservation surgery (OLOPS), at present mainly represented by open partial horizontal laryngectomies (OPHLs). An approach using rigorous selection criteria based on both the general condition of the patient and the local and regional extent of the disease gives excellent oncological and functional results in untreated patients. Similar outcomes, albeit slightly worse, are also obtainable in radio-recurrent and laser-recurrent patients. Troublesome postoperative management and the inconsistency of functional recovery are the main limitations for extensive application of this therapeutic strategy. The future direction is represented by simplification of the indications identifying iso-prognostic sub-categories within the T-stage, wider consensus on rehabilitation protocols, hybrid approaches to the larynx, and open minimally invasive access.

Keywords: laryngeal cancer, partial laryngectomy, supracricoid laryngectomy, supratracheal laryngectomy, salvage surgery, quality of life, outcome, functional results

\section{INTRODUCTION}

In recent years, the introduction of chemoradiation-based organ-sparing protocols (1-3) has demonstrated that larynx preservation is feasible even when this organ is affected by intermediatelocally advanced cancer. This approach, together with associated surgical procedures, has led to a considerable change in the therapeutic approach to laryngeal cancer, characterized by anatomical sparing of the larynx or preservation of its functions $(4,5)$.

Open laryngeal organ preservation surgery (OLOPS) may be applicable as a strategy to spare laryngeal function, preventing permanent tracheostomy (6) with its associated negative aspects. Despite being very rich in techniques and solutions historically, OLOPS has developed over the past 30 years within the field of open partial horizontal laryngectomies (OPHLs) $(4,7)$ since transoral laser microsurgery (TLM) has now universally replaced vertical partial laryngectomies (5).

OPHL has been used extensively as a surgical option in early (I-II) and intermediate stages (III). The excellent reliability of the technique is demonstrated by robust and repeatable oncological outcomes at a similar level to function sparing results $(8,9)$ as long as strict eligibility criteria are applied. Thanks to this rigorous approach, with a further comparative balance between pre- and post-treatment staging, OPHLs provide excellent oncological and functional results as rescue procedures in radio-recurrent (10) and laser-recurrent (11) laryngeal cancer (12). The limitations of OPHLs, procedures not currently universally adopted, lie in the fact that postoperative management is often difficult and residual laryngeal function can vary greatly among 
centers (12); in particular, the quality of vocal recovery can vary immensely, even in the hands of experienced surgeons.

A mini-review of recent literature, focusing on OPHLs, is reported in order to assess the changes which are occurring in open laryngeal organ preservation surgery, based on selection of patients, indications, functional outcomes, strategies, and technique refinements.

\section{HISTORIC LANDMARKS}

In the late 20th century, OLOPS has progressively been adopted as a treatment modality for laryngeal cancer at different stages: early (frequently), intermediate (occasionally, but progressively increasing), and rarely in selected advanced cases.

In 1947, Alonso introduced the concept of OPHL when describing supraglottic laryngectomy (13), and Bocca et al. (14) contributed to the widespread diffusion of the procedure, also expanding its indications.

The logic of a horizontal resection, also applied to glottic and subglottic tumors, was shared by Mayer and Rider in Vienna (15) and became established through more frequent application to intermediate stage tumors (1620). These interventions (21), called "supracricoid partial laryngectomies" (SCPL), have gradually reached consensus in the treatment of more locally advanced laryngeal cancers (most T3). Supratracheal partial laryngectomy (STPL) was first described by Serafini (18). Supracricoid laryngectomy with tracheocricohyoidoepiglottopexy, described in 1996 by Laccourreye et al. (22) as a SCPL extended to the cricoid ring, paved the way for the development of "functional" STPL, which was described by Rizzotto et al. in 2006 (19, 23).

In 2014, the European Laryngological Society introduced a new classification "of the more common procedures according to the extent of resection, including three types of OPHL: type Isupraglottic, type II-supracricoid, and type III-supratracheal" (7). This simple classification facilitated the learning of these interventions by less experienced surgeons, and the comparison of results between different surgeons and institutions.

\section{SELECTION OF PATIENTS}

The preoperative selection of patients is one of the most crucial points in obtaining a good functional outcome. Old age, an important factor when considering a patient for surgery in current practice, is no longer taken to be an exclusion criterion (24) due to the increasing divergence between biological age and chronological age. The current cut-off is shifting to 70 years, with the major focus on biological age. In fact, as demonstrated by Benito et al. using a prediction model, the increased age ( $>70$ years) together with the widening of the intervention and resection of one arytenoid correlates with a greater probability of

\footnotetext{
Abbreviations: MPT, maximum phonation time; OLOPS, open laryngeal organ preservation surgery; OPHL, open partial horizontal laryngectomy; PEG, percutaneous endoscopic gastrostomy; SCPL, supracricoid partial laryngectomy; STPL, supratracheal partial laryngectomy; TL, total laryngectomy; TLM, transoral laser microsurgery; TORS, transoral robotic surgery.
}

severe impairment of swallowing function, thus causing severe aspiration (25). Gallo et al. recently reported similar results when applying a prediction nomogram for dysphagia to 535 patients (26). Simple clinical parameters, coupled with the intermediate degree of hemodynamic stress associated with OLOPS, allow the best candidates to be identified for this procedure: the ability to climb two flights of stairs ( $=4$ METs) (27) as well a Karnofsky index cut-off placed at a level $>80$, the latter corresponding to normal activity with effort (28). Finally, the focus should be on the patient's related exclusion issues (9) as well as on the presence of serious metabolic diseases (e.g., diabetes mellitus), diseases greatly reducing lung function, diseases of the nervous system reducing expectoration and/or the ability to swallow, or severe heart disease (29).

\section{OPHLS IN UNTREATED PATIENTS}

In oncological terms, the most significant feature of OLOPS, represented today essentially by OPHLs, is related to resection of the laryngeal segment affected by the disease with all its anatomical constituents: mucosal layer, membranous layer, submucosal visceral spaces, muscles and corresponding cartilage. Furthermore, the three major categories of OPHL (type I-III) can simply be combined and modulated with posterior enlargement (arytenoid or crico-arytenoid unit) or vertically upward or downward, making them suitable for the management of most laryngeal cancers.

OPHLs are today emerging as the preferred treatment for laryngeal cancer in the early and intermediate stages (rarely T1, $\mathrm{T} 2$, and selected T3), and even less anecdotal is the demonstration of their effectiveness in selected "early" T4a disease (4, 30-34).

After a complete resection, the prognostic outcomes of type I OPHLs, which are certainly the most consolidated ones (more than 60 years after systematic adoption), appear to be comparable to those obtained by TLM $(35,36)$. Despite similar results in terms of survival and laryngeal preservation (37) [5-year diseasespecific survival (DSS) 72 vs. 80\%, 5-year laryngeal preservation rate 80 vs. $86 \%$ ], comparative analysis of laryngeal function (35) has revealed that TLM has a smaller effect on swallowing capacity than open neck supraglottic laryngectomy, resulting in lower morbidity and faster recovery.

Treatment of supraglottic cancers experience less locoregional control than glottic tumors, since they are usually diagnosed at an advanced stage because of a higher incidence of cervical lymph node metastasis (38-42). Even considering the good results obtained by transoral approaches [TLM and transoral robotic surgery (TORS)] $(43,44)$, type I and type IIb OPHLs allow good outcomes in function preservation management of early-intermediate supraglottic cancer (95\% at 5 years) (45). These procedures continue to be indicated in patients with difficult transoral exposure and in the case of bulky tumors.

National Comprehensive Cancer Network guidelines (33) for glottic/supraglottic cancer amenable to larynx preservation include the option of partial laryngectomy for early laryngeal cancer and only for selected T3. The definition of "selected" identifies patients who are fit for an open neck surgical procedure, 
where OPHL is supposed to be the exclusive treatment (T2T3 N0 tumors with anterior commissure or transglottic spread). Very gradually, OPHLs have been adopted as an extreme larynxsparing option in naïve T4a cases, with initial extra-laryngeal extension $(9,32)$.

A problem hindering the standardization of indications on the basis of the T category is the excessive heterogeneity of the CT2cT3 and cT4 categories, both supraglottic and glottic. In fact, less experienced surgeons often find it difficult to understand why, always within the same stage of T, an OPHL is more suitable for some sub-categories of cancer rather than others.

A study on 489 type II-III OPHLs was recently carried out to identify iso-prognostic subcategories in cT3 to cT4a supraglottic/glottic cancers, and also describing their different patterns of spreading, and the modality of endo/extra laryngeal recurrence (46). Based on the anatomical compartmentalization of the larynx matched with a functional parameter (arytenoid mobility), this study allowed identification of the sub-categories in which the indication for OPHL is oncologically sound. In fact, anterior CT3 tumors (tumors without involvement of the posterior paraglottic space and normal arytenoid mobility) can be managed by OPHL; the same concepts and approach could also be adopted in the treatment of cT4aN0 with a minimal anterior extralaryngeal extension. Succo et al. reported that, despite promising results, the OPHL approach should be considered under investigation in posterior cT3 tumors due to clinical and biological behavior similar to cT4a tumors (46). This, however, results in a resident-based method useful to overcome the difficulties of indications arising from the TNM classifications; a similar approach has recently been described for the management of laryngeal cancer by TLM (47).

In patients with early and intermediate T-stage (T2-T3) treated by type II OPHLs, 5-year local control rates are above $90 \%$, and disease-free survival (DFS) is between 70 and $90 \%$ $(8,8,9,9-21,21-30,30,31,31-40,40-54)$. The overall survival (OS) as pooled mean is about $79.7 \%$ and the total laryngectomy completion rate due to aspiration pneumonia is low $(1-3 \%)(6,8,9,25)$.

In 1972, Serafini (18) described a type of OPHL called tracheohyoidoepiglottopexy to manage laryngeal cancer extending to a subglottic site by preserving the apex of the epiglottis and its subsequent pexy with the hyoid bone and the first tracheal rings. The functional results were poor due to the removal of both arytenoids compelling that author to abandon this procedure.

In the 1990s, Laccourreye et al. (23) reported an enlargement of conventional SCPL to the cricoid ring in the case of glottic tumors extending anteriorly to the subglottis. Finally, in 2006, Rizzotto et al. described the current technique of STPL (OPHL type III), allowing outcomes to be obtained which were functionally and oncologically sound (19).

The reported oncological and functional outcomes are still insufficient to adopt unquestionably type III OPHL (19, 22, 23, 55-59). However, these results are certainly interesting and need further confirmation in larger series; patients undergoing OPHL type IIa and type IIIa show "comparable long-term functional outcomes" (58) and therefore OPHL type IIIa, representing an additional option to treat glottic tumors with subglottic extension, can be considered to be a valid surgical option among OLOPS.

In patients affected by intermediate cancer (pT3), the locoregional control (LRC) and DFS at 5 years reach 88.7 and $86.4 \%$, respectively, while in patients with an early extra-laryngeal extension (pT4a), LRC drops to $64.8 \%$ and DFS to $52.7 \%(22,23)$.

A desirable role for a type III OPHL could be that of an enlargement procedure of a type II OPHL when resection margins are proved to be insufficient, without shifting immediately to a total laryngectomy (Table 1).

\section{FUNCTIONAL OUTCOMES}

When analyzing outcomes of OLOPS, great attention must be given to functional outcomes since any treatment has a negative impact on different functions: breathing, swallowing, voice and quality of life (QoL) $(59,60)$. These functional outcomes must be brought to the patient's attention when discussing the different treatment options.

The mean length of hospital stay, removal of the nasogastric tube, and decannulation times are highly variable, ranging between $5-104$ days $(61,62), 10-88$ days $(63,64)$, and $8-105$ days $(61,65)$, respectively; however, lower variability is reported in decannulation rates $(85.7-100 \%)(66,67)$, testifying to the good patency of the neoglottis following OPHL.

Swallowing functional outcomes are generally good after OPHL, although not overlapping in the different series; however, it is even more important to determine the reasons for the extreme differences in the adopted rehabilitation protocols. During the early postoperative period, aspiration rates are higher ranging from 30 to $100 \%(67,68)$; dysphagia is more frequent for liquids rather than solids and spontaneous recovery is observed within 6 months in $15-80.4 \%$ of cases $(25,69)$, and a free diet regime is achieved in the first postoperative year in the majority of patients $(53-100 \%)(70,71)$. In the longer term, most patients report occasional well-tolerated episodes of aspiration while aspiration pneumonia occurs in $0-21.7 \%$ of cases $(70,72)$. High-grade dysphagia and frequent aspiration pneumonia clearly affect the physical and emotional condition of patients.

Voice impairment has been recognized as the real Achilles' heel in patients undergoing OPHL type II-III, significantly compromising the emotional balance. Schindler et al. report that, in OPHL type II and III patients, the voice is produced by a neoglottis that is inherently patent at rest and in turn demonstrates substantially less volitionally induced valuing activity and resistance to airflow during voicing (71); a significant loss of air during phonation requires an increase in expiratory pressure and strength in closure of the neoglottis to achieve rigidity and improve vibration, thus producing a strained, deep and asexualized voice, which is difficult to modulate and to raise; speech is composed of short sentences, because patients are short of breath (73). Schindler et al. (12) state that maximum phonation time (MPT) implies adequacy of air support for speech and is quite low in OPHL type II-III patients, probably due to the lower resistance of the neoglottis with consequent air 
TABLE 1 | Three to five year local control (LC) rates in treatment-naive patients.

\begin{tabular}{|c|c|c|c|c|c|c|}
\hline Author & Publication year & T stage & Type OPHL & No. of Pts & 3-year LC (\%) & 5-year LC (\%) \\
\hline Adamopoulos & 1997 & & 1 & 92 & 92.4 & \\
\hline Bocca & 1983 & & 1 & 407 & & 86.5 \\
\hline Succo & 1999 & & 1 & 142 & & 78 \\
\hline Spriano & 1997 & $1-2$ & $|-| \mid b$ & 66 & & 95.5 \\
\hline Maurizi & 1999 & & 1 & 132 & & 74 \\
\hline Prades & 2005 & & 1 & 110 & 90.3 & \\
\hline Succo (part A) & 2016 & 2 & $\|-I\|$ & 216 & & 97.5 \\
\hline Succo (part B) & 2016 & $3-4 a$ & $\|-\| \|$ & 555 & & 90.6 \\
\hline Chevalier & 1997 & $2-3$ & $\|$ & 112 & & 94.6 \\
\hline Mercante & 2013 & 3 & $\|$ & 32 & 96.2 & 96.2 \\
\hline Lima & 2006 & $3-4$ & $\|$ & 43 & & 85 \\
\hline Laccourreye & 1996 & $2-4$ & IIla & 21 & & 88.9 \\
\hline Dufour & 2004 & 3 & $\|a-\| b$ & 118 & 93.5 & 91.4 \\
\hline Rizzotto & 2015 & $3-4 a$ & |lla-IIlb & 115 & & 69.6 \\
\hline Schwaab & 2001 & $1-2-3-4$ & Ilb & 146 & & 95.8 \\
\hline Gallo & 2005 & $1-2-3-4$ & Ila-llb & 253 & & 91.3 \\
\hline Laudadio & 2006 & $1 b-2-3-4$ & Ila-llb & 206 & & 93.2 \\
\hline Laccourreye & 1998 & $3-4$ & Illb & 60 & & 98.3 \\
\hline
\end{tabular}

loss during phonation (67); thus, in order to compensate for the air wastage during phonation, the SCPL-STPL patient needs to increase neoglottal resistance and subglottic pressure with consequent vocal fatigue because of the increased physiological effort required to phonate. Interestingly, MPT appears not to be significantly affected by arytenoid removal, suggesting welltolerated recovery of glottal closure after removal of the ipsilateral arytenoid and reconstruction of the neoglottis $(12,74)$.

Aiming to improve the sphincteric action of the larynx after OPHL a surgical strategy based on injection laryngoplasty with different materials can be effectively adopted in rehabilitation of dysphagia and dysphonia (75).

Few reports have focused on post-OPHL QoL and data are contradictory. QoL is a condition which is strongly influenced by psycho-social, ethnic and cultural factors. When swallowingrelated QoL was analyzed, data indicate that dysphagia has only a limited impact on everyday life. Moreover, it should be noted that the vast majority of patients take food without restrictions $(62,65)$.

Schindler and colleagues still state that "since the voice is mainly used for everyday verbal communication, it is possible that vocal QoL is perceived by the patient as not being significantly compromised, even though the voice per se is rather poor" $(71,76)$.

\section{OPHL AS SALVAGE SURGERY}

In recent years, the increasing attention given not only to tumor control but also to preservation of functionality has resulted in a gradual replacement of up-front total laryngectomy (TL) by radiation (RT), chemoradiation (CRT), TLM and OPHLs $(2,55,77,78)$.
Local relapse after RT and TLM is rare for T1 (range 5$13 \%$ ) while for T2 laryngeal cancer, it ranges from 25 to $40 \%$ $(79,80)$. Steiner et al. have observed that the pattern of recurrence often demonstrates aggressive behavior arising in a field where lymphatic drainage is unpredictable and is associated with poor control rates (81). Diagnosis of recurrence is made difficult because of radiation sequelae such as edema or the frequent submucosal spreading after TLM determining a reduction in sensitivity/specificity of conventional diagnostic tools.

Several studies in the last decade have focused on the potentiality of OPHLs in terms of local control and functional results after RT and TLM $(10,11)$. Some studies have confirmed the feasibility of the technique, showing that the recurrence occurs in more advanced stage (82-91).

Local control at 24 months ranges between 70 and 95\% (83$86,88-90)$, DFS at 36 months between 70 and $90 \%(83-87,89)$, while OS at 5 years stands between 70 and $90 \%(83-86,92)$.

Sometimes a salvage or completion TL is required. The organ sparing rate is $85.2 \%$, while the mean decannulation rate is $92.1 \%$ in over 200 patients reported in the literature. Laryngeal stenosis is a redoubtable side-effect (3.9\% of cases) making it difficult to remove the tracheostomy. An efficient swallowing ability is achievable in almost $90 \%$ of cases. A gastrostomy dependence rate in $3.5 \%$ and aspiration pneumonia in $6.4 \%$ were reported in a cohort of 221 patients (83-86).

Data relating to phonatory outcomes after salvage OPHL are rarely reported in the literature. Pellini et al. reported an "acceptable quality of voice for most patients" (82), very perturbed and hoarse in the majority of patients with maximum phonation time (MPT) ranging from 3 to $18 \mathrm{~s}$ (mean, $8.3 \mathrm{~s}$ ). Similar results were also reported by several other authors $(83,85,87)$ (Table 2). 
TABLE 2 | Three to five year local control (LC) rates in pre-treated patients.

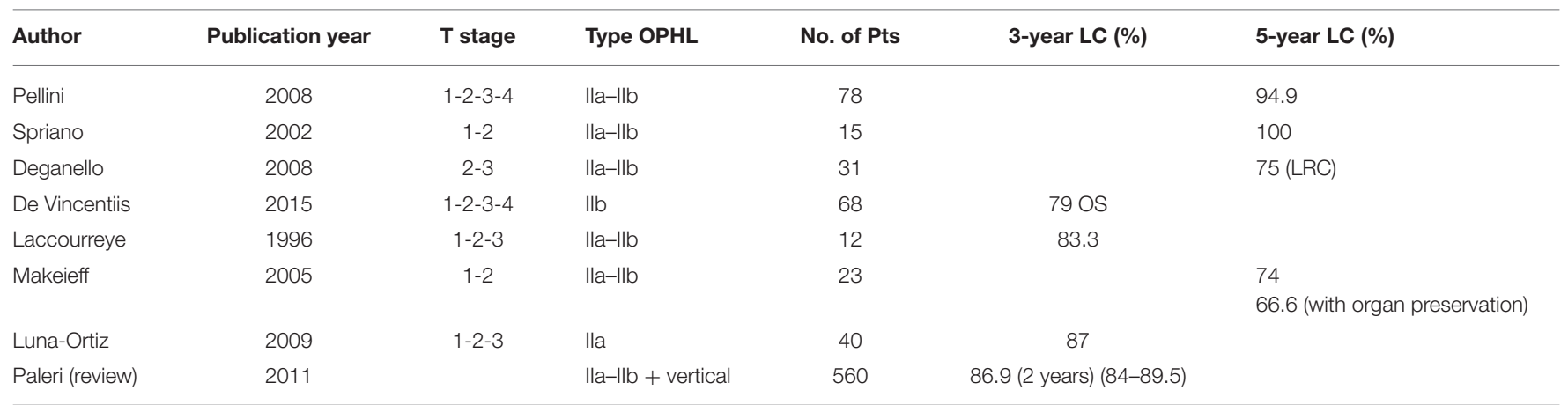

LRC, locoregional control; OS, overall survival.

\section{TECHNICAL IMPROVEMENTS}

Although there is a consensus on standard surgical techniques for OPHLs, the advent of robotic surgery has opened a window on the possibility of performing this surgery using hybrid approaches combining a limited transcervical approach and TORS $(93,94)$. The hybrid approaches, offering direct visualization during tumor resection before laryngotomy and full closure of the laryngopharynx defect, might facilitate postoperative recovery making this larynx preservation procedure more accessible to patients and surgeons.

Functional outcomes suggest that the procedure is repeatable and sufficiently safe (93).

Aiming to further reduce the overall impact of surgery, Spriano et al. have recently proposed a limited lateral cervicotomy approach which preserves anterior healthy tissue with evident better aesthetic outcomes and probably improved functional outcomes as well $(95,96)$.

\section{CONCLUSION}

Why is interest in partial laryngeal surgery growing again today? Single and multi-institutional series support OLOPS by OPHLs as a safe technique in the management of laryngeal cancer in

\section{REFERENCES}

1. The Department of Veterans Affairs Laryngeal Cancer Study Group, Wolf GT, Fisher SG, Hong WK, Hillman R, Spaulding M, Laramore GE, et al. Induction chemotherapy plus radiation compared with surgery plus radiation in patients with advanced laryngeal cancer. N Engl J Med. (1991) 324:168590. doi: 10.1056/NEJM199106133242402

2. Forastiere AA, Goepfert H, Maor M, Maor M, Pajak TF, Weber $\mathrm{R}$, et al. Concurrent chemotherapy and radiotherapy for organ preservation in advanced laryngeal cancer. $N$ Engl J Med. (2003) 349:2091-8. doi: 10.1056/NEJMoa031317

3. Forastiere AA, Zhang Q, Weber RS, Maor MH, Goepfert H, Pajak TF, et al. Long-term results of RTOG 91-11: a comparison of three nonsurgical treatment strategies to preserve the larynx in patients with locally advanced larynx cancer. J Clin Oncol. (2013) 31:845-52. doi: 10.1200/JCO.2012. 43.6097 carefully selected stages, having standardized high OS, LRC, and DFS as well as acceptable functional outcomes.

Similar outcomes, although worse functionally, can be achieved in radio-recurrent or TLM-recurrent patients, determining inclusion of these procedures as a salvage option in selected patients.

Great variability is still observed in functional results, making research seeking a wide consensus on rehabilitation after OPHLs the field most likely to witness extensive improvements for the patient.

\section{AUTHOR CONTRIBUTIONS}

EC: surgeon who performed study conception and design, drafting the article, final approval of the version to be published. GS: surgeon who performed the final approval of the version to be published.

\section{FUNDING}

These studies on laryngeal cancer have been funded: Regione Piemonte Ad Functionem (years 2015-2018); FPRC 5xmille 2016 Ministero della Salute Progetto ARDITE; Fondi Ricerca Corrente 2018, Ministero della Salute.

4. Thomas L, Drinnan M, Natesh B, Mehanna H, Jones T, Paleri V. Open conservation partial laryngectomy for laryngeal cancer: a systematic review of English language literature. Cancer Treat Rev. (2012) 38:20311. doi: $10.1016 /$ j.ctrv.2011.05.010

5. Peretti G, Piazza C, Cocco D, De Benedetto L, Del Bon F, Redaelli De Zinis LO, et al. Transoral $\mathrm{CO}(2)$ laser treatment for $\mathrm{T}(\mathrm{is})-\mathrm{T}(3)$ glottic cancer: the University of Brescia experience on 595 patients. Head Neck. (2010) 32:977-83. doi: 10.1002/hed.21278

6. Tomeh C, Holsinger C. Laryngeal cancer. Curr Opin Otolaryngol Head Neck Surg. (2014) 22:147-53. doi: 10.1097/MOO.0000000000000032

7. Succo G, Peretti G, Piazza C, Remacle M, Eckel HE, Chevalier D, et al. Open partial horizontal laryngectomies: a proposal for classification by the working committee on nomenclature of the European Laryngological Society. Eur Arch Otorhinolaryngol. (2014) 271:2489-96. doi: 10.1007/s00405-014-3024-4

8. Succo G, Crosetti E, Bertolin A, Lucioni M, Caracciolo A, Panetta V, et al. Benefits and drawbacks of open partial horizontal laryngectomies, Part A: 
early- to intermediate-stage glottic carcinoma. Head Neck. (2016) 38 (Suppl. 1):E333-40. doi: 10.1002/hed.23997

9. Succo G, Crosetti E, Bertolin A, Succo G, Crosetti E, Bertolin A, et al. Benefits and drawbacks of open partial horizontal laryngectomies, Part B: intermediate and selected advanced stage laryngeal carcinoma. Head Neck. (2016) 38 (Suppl. 1):E649-57. doi: 10.1002/hed.24064

10. Marioni G, Marchese-Ragona R, Kleinsasser N, Lionello M, Lawson G, Hagen $\mathrm{R}$, et al. Partial laryngeal surgery in recurrent carcinoma. Acta Otolaryngol. (2015) 135:119-24. doi: 10.3109/00016489.2014.969811

11. Lucioni M, Bertolin A, Lionello M, Giacomelli L, Rizzotto G, Marioni G. Open partial horizontal laryngectomy for salvage after failure of CO2 laserassisted surgery for glottic carcinoma. Eur Arch Otorhinolaryngol. (2016) 273:169-75. doi: 10.1007/s00405-015-3734-2

12. Schindler A, Pizzorni N, Mozzanica F, Fantini M, Ginocchio D, Bertolin A, et al. Functional outcomes after supracricoid laryngectomy: what do we not know and what do we need to know? Eur Arch Otorhinolaryngol. (2016) 273:3459-75. doi: 10.1007/s00405-015-3822-3

13. Alonso J. Conservative surgery of cancer of the larynx. Trans Am Acad Ophthalmol Otolaryngol. (1947) 51:633-42.

14. Bocca E, Pignataro O, Oldini C, Sambataro G, Cappa C. Extended supraglottic laryngectomy. Review of 84 cases. Ann Otol Rhinol Laryngol. (1987) 96:3846. doi: 10.1177/000348948709600406

15. Mayer E, Rider W. Technique de laryngectomie permettant de conserver la permeabilité respiratoire (La cricohyoidepexie). Ann Otolaryngol Chir Cervicofac. (1959) 76:677-81.

16. Labayle S, Bismuth R. La laryngectomie totale avec reconstruction. Ann Otolaryngol Chir Cervicofac. (1971) 88:219-28.

17. Piquet J, Desaulty A, Decroix G. La crico-hyoido-épiglotto-pexie. Technique opératoire et résultats fonctionnels. Ann Otolaryngol Chir Cervicofac. (1974) 91:681-90.

18. Serafini I. Reconstructive laryngectomy. Rev Laryngol Otol Rhinol. (1972) 93:23-38.

19. Rizzotto G, Succo G, Lucioni M, Pazzaia T. Subtotal laryngectomy with tracheohyoidopexy: a possible alternative to total laryngectomy. Laryngoscope. (2006) 116:1907-17. doi: 10.1097/01.mlg.0000236085.85790.d5

20. Weinstein G, El-Sawy M, Ruix C, Dooley P, Chalian A, El-Sayed MM, et al. Laryngeal preservation with supracricoid partial laryngectomy results in improved quality of life when compared with total laryngectomy. Laryngoscope. (2001) 111:191-9. doi: 10.1097/00005537-200102000-00001

21. Chevalier D, Laccourreye O, Brasnu D, Laccourreye H, Piquet JJ. Cricohyoidoepiglottopexy for glottic carcinoma with fixation or impaired motion of the true vocal cord: 5-year oncologic results with 112 patients. Ann Otol Rhinol Laryngol. (1997) 106:364-9. doi: 10.1177/0003489497106 00502

22. Laccourreye O, Brasnu D, Jouffre V, Couloigner V, Naudo P, Laccourreye H. Supra-cricoid partial laryngectomy extended to the anterior arch of the cricoid with tracheo-crico-hyoido-epiglottopexy. Oncologic and functional results. Ann Otolaryngol Chir Cervicofac. (1996) 113:15-9.

23. Succo G, Bussi M, Presutti L, Cirillo S, Crosetti E, Bertolin A, et al. Supratracheal laryngectomy: current indications and contraindications. Acta Otorhinolaryngol Ital. (2015) 35:146-56.

24. Schindler A, Favero E, Capaccio P, Albera R, Cavalot AL, Ottaviani F. Supracricoid laryngectomy: age influence on long-term functional results. Laryngoscope. (2009) 119:1218-25. doi: 10.1002/lary.20172

25. Benito J, Holsinger F, Pérez-Martín A, Garcia D, Weinstein GS, Laccourreye O. Aspiration after supracricoid partial laryngectomy: incidence, risk factors, management, and outcomes. Head Neck. (2011) 33:679-85. doi: 10.1002/hed.21521

26. Gallo O, Locatello LG, Larotonda G, Napoleone V, Cannavicci A. Nomograms for prediction of postoperative complications in open partial laryngeal surgery. J Surg Oncol. (2018) 118:1050-57. doi: 10.1002/jso.25232

27. Eagle KA, Berger PB, Calkins H, Chaitman BR, Ewy GA, Fleischmann $\mathrm{KE}$, et al. CC/AHA guideline update for perioperative cardiovascular evaluation for noncardiac surgery - executive summary. A report of the American College of Cardiology/American Heart Association Task Force on Practice Guidelines. (Committee to Update the 1996 Guidelines on Perioperative Cardiovascular Evaluation for Noncardiac Surgery). Anesth Analg. (2002) 94:1052-64. doi: 10.1097/00000539-200205000-00002
28. List MA, Ritter-Sterr C, Lansky SB. A performance status scale for head and neck cancer patients. Cancer. (1990) 66:564-9. doi: 10.1002/1097-0142(19900801)66:3\&lt;564::AIDCNCR2820660326\&gt;3.0.CO;2-D

29. Crosetti E, Caracciolo A, Molteni G, Sprio AE, Berta GN, Presutti L, et al. Unravelling the risk factors that underlie laryngeal surgery in elderly. Acta Otorhinolaryngol Ital. (2016) 36:185-93. doi: 10.14639/0392-100X-817

30. Mercante G, Grammatica A, Battaglia P, Cristalli G, Pellini R, Spriano G. Supracricoid partial laryngectomy in the management of T3 laryngeal cancer. Otolaryngol Head Neck Surg. (2013) 149:714-20. doi: 10.1177/0194599813500018

31. Lima R, Freitas E, Dias F, Barbosa MM, Kligerman J, Soares JR, et al. Supracricoid laryngectomy with cricohyoidoepiglottopexy for advanced glottic cancer. Head Neck. (2006) 28:481-6. doi: 10.1002/hed.20361

32. Laccourreye O, Brasnu D, Biacabe B, Hans S, Seckin S, Weinstein G. Neo-adjuvant chemotherapy and supracricoid partial laryngectomy with cricohyoidopexy for advanced endolaryngeal carcinoma classified as T3-T4: 5-years oncologic results. Head Neck. (1998) 20:595-9. doi: 10.1002/(SICI)1097-0347(199810)20:7\&lt;595::AIDHED3\&gt;3.0.CO;2-K

33. National Comprehensive Cancer Network. Clinical Practice Guidelines in Oncology Version 1. (2016).

34. Sessions D, Lenox J, Spector GJ. Supraglottic laryngeal cancer: analysis of treatment results. Laryngoscope. (2005) 115:140210. doi: 10.1097/01.MLG.0000166896.67924.B7

35. Peretti G, Piazza C, Cattaneo A, De Benedetto L, Martin E, Nicolai P. Comparison of functional outcomes after endoscopic versus open-neck supraglottic laryngectomies. Ann Otol Rhinol Laryngol. (2006) 115:82732. doi: 10.1177/000348940611501106

36. Vilaseca I, Blanch JL, Berenguer J, Grau JJ, Verger E, Muxí Á, et al. Transoral laser microsurgery for locally advanced (T3-T4a) supraglottic squamous cell carcinoma: sixteen years of experience. Head Neck. (2016) 38:10507. doi: 10.1002/hed.24408

37. Cabanillas R, Rodrigo J, Llorente J, Suárez C. Oncologic outcomes of transoral laser surgery of supraglottic carcinoma compared with a transcervical approach. Head Neck. (2008) 30:750-5. doi: 10.1002/hed.20778

38. Iro H, Waldfahrer F, Altendorf-Hofmann A, Weidenbecher M, Sauer R, Steiner W. Transoral laser surgery of supraglottic cancer: follow-up of 141 patients. Arch Otolaryngol Head Neck Surg. (1998) 124:124550. doi: 10.1001/archotol.124.11.1245

39. Prades JM, Simon PG, Timoshenko AP, Dumollard JM, Schmitt T, Martin C. Extended and standard supraglottic laryngectomies: a review of 110 patients. Eur Arch Otorhinolaryngol. (2005) 262:947-52. doi: 10.1007/s00405-004-0882-1

40. Adamopoulos G, Yiotakis J, Stavroulaki P, Manolopoulos L. Modified supracricoid partial laryngectomy with cricohyoidopexy: series report and analysis of results. Otolaryngol Head Neck Surg. (2000) 123:28893. doi: $10.1067 / \mathrm{mhn} .2000 .104779$

41. Bocca E, Pignataro O, Oldini C. Supraglottic laryngectomy: 30 years of experience. Ann Otol Rhinol Laryngol. (1983) 92:14-8. doi: 10.1177/000348948309200104

42. Maurizi M, Paludetti G, Galli J, Ottaviani F, D’Abramo G, Almadori G. Oncological and functional outcome of conservative surgery for primary supraglottic cancer. Eur Arch Otorhinolaryngol. (1999) 256:28390. doi: 10.1007/s004050050247

43. Peretti G, Piazza C, Penco S, Antori G, Del Bon F, Garofolo S, et al. Transoral laser microsurgery as primary treatment for selected T3 glottic and supraglottic cancers. Head Neck. (2016) 38:1107-12. doi: 10.1002/hed.24424

44. Ansarin M, Zorzi S, Massaro M, Tagliabue M, Proh M, Giugliano G, et al. Transoral robotic surgery vs transoral laser microsurgery for resection of supraglottic cancer: a pilot surgery. Int J Med Robot. (2014) 10:10712. doi: $10.1002 / \mathrm{rcs} .1546$

45. Spriano G, Antognoni P, Piantanida R, Varinelli D, Luraghi $\mathrm{R}$, Cerizza $\mathrm{L}$, et al. Conservative management of T1-T2N0 supraglottic cancer: a retrospective study. Am J Otolaryngol. (1997) 18:299-305. doi: 10.1016/S0196-0709(97)90023-5

46. Succo G, Crosetti E, Bertolin A, Piazza C, Molteni G, Cirillo S, et al. Treatment for T3 to T4a laryngeal cancer by open partial horizontal laryngectomies: 
prognostic impact of different pathologic tumor subcategories. Head Neck. (2018) 40:1897-908. doi: 10.1002/hed.25176

47. Piazza C, Filauro M, Paderno A, Marchi F, Perotti P, Morello R, et al. Threedimensional map of isoprognostic zones in glottic cancer treated by transoral laser microsurgery as a unimodal treatment strategy. Front Oncol. (2018) 8:175. doi: 10.3389/fonc.2018.00175

48. Peretti G, Piazza C, Mensi MC, Magnoni L, Bolzoni A. Endoscopic treatment of cT2 glottic carcinoma: prognostic impact of different pT subcategories. Ann Otol Rhinol Laryngol. (2005) 114:579-86. doi: 10.1177/0003489405 11400801

49. Dufour X, Hans S, De Mones E, Brasnu D, Ménard M, Laccourreye O. Local control after supracricoid partial laryngectomy for "advanced" endolaryngeal squamous cell carcinoma classified as T3. Arch Otolaryngol Head Neck Surg. (2004) 130:1092-9. doi: 10.1001/archotol.130.9.1092

50. Laccourreye O, Muscatello L, Laccourreye L, Naudo P, Brasnu D, Weinstein G. Supracricoid partial laryngectomy with cricohyoidoepiglottopexy for "early" glottic carcinoma classified as T1-T2N0 invading the anterior commissure. Am J Otolaryngol. (1997) 18:385-90. doi: 10.1016/S0196-0709(97)90058-2

51. Akbas Y, Demireller A. Oncologic and functional results of supracricoid partial laryngectomy with cricohyoidopexy. Otolaryngol Head Neck Surg. (2005) 132:783-7. doi: 10.1016/j.otohns.2005.01.030

52. Ndiaye M, Dassonville O, Poissonnet G, Vallicioni J, Bozec A, Santini J, et al. The supracricoid laryngectomy with cricohyoidopexy. Carcinological and functional results. 23 cases report of the Centre A Lacassagne (Nice). Rev Laryngol Otol Rhinol. (2004) 125:113-6.

53. Gallo A, Manciocco V, Simonelli M, Pagliuca G, D’Arcangelo E, de Vincentiis M. Supracricoid partial laryngectomy in the treatment of laryngeal cancer: univariate and multivariate analysis of prognostic factors. Arch Otolaryngol Head Neck Surg. (2005) 131:620-5. doi: 10.1001/archotol.131.7.620

54. Schwaab G, Kolb F, Julieron M, Janot F, Le Ridant AM, Mamelle $\mathrm{G}$, et al. Subtotal laryngectomy with cricohyoidopexy as first treatment procedure for supraglottic carcinoma: Institut Gustave-Roussy experience (146 cases, 1974-1997). Eur Arch Otorhinolaryngol. (2001) 258:2469. doi: $10.1007 / \mathrm{s} 004050100348$

55. Rizzotto G, Crosetti E, Lucioni M, Bertolin A, Monticone V, Sprio AE, et al. Oncologic outcomes of supratracheal laryngectomy: critical analysis. Head Neck. (2015) 37:1417-24. doi: 10.1002/hed.23773

56. Schindler A, Fantini M, Pizzorni N, Crosetti E, Mozzanica F, Bertolin A, et al. Swallowing, voice, and quality of life after supratracheal laryngectomy: preliminary long-term results. Head Neck. (2015) 37:55766. doi: $10.1002 /$ hed.23636

57. Calvas OIJ, Ramos DM, Matos LL, Kulcsar MAV, Dedivitis RA, Brandão LG, et al. Oncological results of surgical treatment versus organ-function preservation in larynx and hypopharynx cancer. Rev Assoc Med Bras. (2017) 63:1082-89. doi: 10.1590/1806-9282.63.12.1082

58. Schindler A, Pizzorni N, Fantini M, Crosetti E, Bertolin A, Rizzotto G, et al. Long-term functional results after open partial horizontal laryngectomy type IIa and type IIIa: a comparison study. Head Neck. (2016) 38 (Suppl. 1):E1427-35. doi: 10.1002/hed.24254

59. Weinstein G, Lacourreye O, Rassekh C. Conservation laryngeal surgery. In: Cummings CW, Fredrickson JM, Harker LA, Krause CJ, Richardson MA, Schuller DE, editors. Otolaryngology-Head and Neck Surgery, 3rd ed. St. Louis, MO: Mosby Inc (1998). p. 2200-28.

60. Crosetti E, Fantini M, Arrigoni G, Salonia L, Lombardo A, Atzori A et al. Telephonic voice intelligibility after laryngeal cancer treatment: is therapeutic approach significant? Eur Arch Otolaryngol. (2017) 274:33746. doi: 10.1007/s00405-016-4217-9

61. Gonçalves A, Bertelli A, Malavasi T, Kikuchi W, Rodrigues AN, Menezes MB. Results after supracricoid horizontal partial laryngectomy. Auris Nasus Larynx. (2010) 37:84-8. doi: 10.1016/j.anl.2009.04.015

62. Nakayama M, Okamoto M, Miyamoto S, Takeda M, Yokobori S, Masaki $\mathrm{T}$, et al. Supracricoid laryngectomy with cricohyoidoepiglotto-pexy or cricohyoido-pexy: experience on 32 patients. Auris Nasus Larynx. (2008) 35:77-82. doi: 10.1016/j.anl.2007.04.018

63. Woisard V, Puech M, Yardeni E, Serrano E, Pessey JJ. Deglutition after supracricoid laryngectomy: compensatory mechanisms and sequelae. Dysphagia. (1996) 11:265-9. doi: 10.1007/BF00265213
64. Clayburgh D, Graville D, Palmer A, Schindler J. Factors associated with supracricoid laryngectomy functional outcomes. Head Neck. (2013) 35:1397403. doi: 10.1002/hed.23144

65. Laccoureye O, Brasnu D, Périé S, Muscatello L, Ménard M, Weinstein G. Supracricoid partial laryngectomies in the elderly: mortality; complications, and functional outcome. Laryngoscope. (1998) 108:237-42. doi: 10.1097/00005537-199802000-00015

66. Rizzotto G, Crosetti E, Lucioni M, Succo G. Subtotal laryngectomy: outcomes of 469 patients and proposal of a comprehensive and simplified classification of surgical procedures. Eur Arch Otorhinolaryngol. (2012) 269:1635-46. doi: 10.1007/s00405-012-1928-4

67. Laccoureye O, Salzer S, Brasnu D, Shen W, Laccourreye H, Weinstein GS. Glottic carcinoma with a fixed true vocal cord: outcomes after neoadjuvant chemotherapy and supracricoid partial laryngectomy with cricohyoidoepiglottopexy. Otolaryngol Head Neck Surg. (1996) 114:4006. doi: 10.1016/S0194-5998(96)70209-7

68. Lewin J, Hutcheson K, Barringer D, May AH, Roberts DB, Holsinger FC, et al. Functional analysis of swallowing outcomes after supracricoid partial laryngectomy. Head Neck. (2008) 30:559-66. doi: 10.1002/hed.20738

69. Pinar E, Imre A, Calli C, Oncel S, Katilmis H. Supracricoid partial laryngectomy: analyses of oncologic and functional outcomes. Otolaryngol Head Neck Surg. (2012) 147:1093-8. doi: 10.1177/0194599812457334

70. Portas J, Queija D, Arine L, Ferreira AS, Dedivitis RA, Lehn CN, et al. Voice and swallowing disorders: functional results and quality of life following supracricoid laryngectomy with cricohyoidoepiglottopexy. Ear Nose Throat J. (2009) 88:E23-30.

71. Schindler A, Favero E, Nudo S, Albera R, Schindler O, Cavalot AL. Longterm voice and swallowing modifications after supracricoid laryngectomy: objective, subjective, and self-assessment data. Am J Otolaryngol. (2006) 27:378-83. doi: 10.1016/j.amjoto.2006.01.010

72. Simonelli M, Ruoppolo G, De Vincentiis M, Di Mario M, Calcagno P, Vitiello C, et al. Swallowing ability and chronic aspiration after supracricoid partial laryngectomy. Otolaryngol Head Neck Surg. (2010) 142:873-8. doi: 10.1016/j.otohns.2010.01.035

73. Bron L, Pasche P, Brossard E, Monnier P, Schweizer V. Functional analysis after supracricoid partial laryngectomy with cricohyoidoepiglottopexy. Laryngoscope. (2002) $112(7 \mathrm{Pt}$ 1):1289-93. doi: 10.1097/00005537-200207000-00027

74. Torrejano G, Guimarães I. Voice quality after supracricoid laryngectomy and total laryngectomy with insertion of voice prosthesis. J Voice. (2009) 23:240-6. doi: 10.1016/j.jvoice.2007.08.005

75. Ricci Maccarini A, Stacchini M, Salsi D, Padovani D, Pieri F, Casolino D. Surgical rehabilitation of dysphagia after partial laryngectomy. Acta Otorhinolaryngol Ital. (2007) 27:294-8.

76. Schindler A, Mozzanica F, Ginocchio D, Invernizzi A, Peri A, Ottaviani F. Voice-related quality of life in patients after total and partial laryngectomy. Auris Nasus Larynx. (2012) 39:77-83. doi: 10.1016/j.anl.2011.03.009

77. Adelstein D, Li Y, Adams GL, Wagner H Jr., Kish JA, Ensley JF, et al. An intergroup phase III comparison of standard radiation therapy and two schedules of concurrent chemoradiotherapy in patients with unresectable squamous cell head and neck cancer. J Clin Oncol. (2003) 21:92-8. doi: 10.1200/JCO.2003.01.008

78. Canis M, Martin A, Ihler F, Wolff HA, Kron M, Matthias C, et al. Transoral laser microsurgery in treatment of pT2 and pT3 glottic laryngeal squamous cell carcinoma-results of 391 patients. Head Neck. (2014) 36:85966. doi: 10.1002/hed.23389

79. Budach W, Hehr T, Budach V, Belka C, Dietz K. A meta-analysis of hyperfractionated and accelerated radiotherapy and combined chemotherapy and radiotherapy regimens in unresected locally advanced squamous cell carcinoma of the head and neck. BMC Cancer. (2006) 6:28. doi: 10.1186/1471-2407-6-28

80. Bonner J, Harari P, Giralt J, Azarnia N, Shin DM, Cohen RB, et al. Radiotherapy plus cetuximab for squamous-cell carcinoma of the head and neck. N Engl J Med. (2006) 354:567-78. doi: 10.1056/NEJMoa053422

81. Steiner W, Vogt P, Ambrosch P, Kron M. Transoral carbon dioxide laser microsurgery for recurrent glottic carcinoma after radiotherapy. Head Neck. (2004) 26:477-84. doi: 10.1002/hed.20009 
82. Pellini R, Pichi B, Ruscito P, Ceroni AR, Caliceti U, Rizzotto G, et al. Supracricoid partial laryngectomies after radiation failure: a multiinstitutional series. Head Neck. (2008) 30:372-9. doi: 10.1002/hed.20709

83. Spriano G, Pellini R, Romano G, Muscatello L, Roselli R. Supracricoid partial laryngectomy as salvage surgery after radiation failure. Head Neck. (2002) 24:759-65. doi: 10.1002/hed.10117

84. Marchese-Ragona R, Marioni G, Chiarello G, Staffieri A, Pastore A. Supracricoid laryngectomy with cricohyoidopexy for recurrence of earlystage glottic carcinoma after irradiation. Long-term oncological and functional results. Acta Otolaryngol. (2005) 125:91-5. doi: 10.1080/000164804 10017927

85. Piazza C, Peretti G, Cattaneo A, Garrubba F, De Zinis LO, Nicolai P. Salvage surgery after radiotherapy for laryngeal cancer: from endoscopic resections to open-neck partial and total laryngectomies. Arch Otolaryngol Head Neck Surg. (2007) 133:1037-43. doi: 10.1001/archotol.133.10.1037

86. Deganello A, Gallo O, De Cesare J, Ninu MB, Gitti G, de' Campora L, et al. Supracricoid partial laryngectomy as salvage surgery for radiation therapy failure. Head Neck. (2008) 30:1064-71. doi: 10.1002/hed.20837

87. De Vincentiis M, De Virgilio A, Bussu F, Gallus R, Gallo A, Bastanza G, et al. Oncologic results of the surgical salvage of recurrent laryngeal squamous cell carcinoma in a multicentric retrospective series: emerging role of supracricoid partial laryngectomy. Head Neck. (2015) 37:84-91. doi: 10.1002/ hed. 23563

88. Laccourreye O, Weinstein G, Naudo P, Cauchois R, Laccourreye H, Brasnu D. Supracricoid partial laryngectomy after failed laryngeal radiation therapy. Laryngoscope. (1996) 106:495-8. doi: 10.1097/00005537-199604000-00019

89. Makeieff M, Venegoni D, Mercante G, Crampette L, Guerrier B. Supracricoid partial laryngectomies after failure of radiation therapy. Laryngoscope. (2005) 115:353-7. doi: 10.1097/01.mlg.0000154751.86431.41

90. León X, López M, García J, Viza I, Orús C, Quer M. Supracricoid laryngectomy as salvage surgery after failure of radiation therapy. Eur Arch Otorhinolaryngol. (2007) 264:809-14. doi: 10.1007/s00405-007-0259-3
91. Luna-Ortiz K, Pasche P, Tamez-Velarde M, Villavicencio-Valencia V. Supracricoid partial laryngectomy with cricohyoidoepiglottopexy in patients with radiation therapy failure. World J Surg Oncol. (2009) 7:101. doi: 10.1186/1477-7819-7-101

92. Paleri V, Thomas L, Basavaiah N, Drinnan M, Mehanna H, Jones $T$. Oncologic outcomes of open conservation laryngectomy for radiorecurrent laryngeal carcinoma: a systematic review and meta-analysis of Englishlanguage literature. Cancer. (2011) 117:2668-76. doi: 10.1002/cncr.25831

93. Morisod B, Guinchard AC, Gorphe P, Schweizer V, Sandu K, Simon C. Transoral robotic-assisted supracricoid partial laryngectomy with cricohyoidoepiglottopexy: procedure development and outcomes of initial cases. Head Neck. (2018) 40:2254-62. doi: 10.1002/hed.25332

94. Nakayama M, Holsinger CF, Orosco RK. Hybrid supracricoid partial laryngectomy with cricohyoidoepiglottopexy via transoral robotic surgery. Laryngoscope. (2018). doi: 10.1002/lary.27628. [Epub ahead of print].

95. Spriano G, Mercante G, Cristalli G, Pellini R, Ferreli F. Lateral cervical approach for supracricoid partial laryngectomy. Am J Otolaryngol. (2017) 38:598-602. doi: 10.1016/j.amjoto.2017.06.011

96. Laudadio P, Presutti L, Dall'olio D, Cunsolo E, Consalici R, Amorosa L, et al. Supracricoid laryngectomies: long-term oncological and functional results. Acta Otolaryngol. (2006) 126:640-9. doi: 10.1080/00016480500469024

Conflict of Interest Statement: The authors declare that the research was conducted in the absence of any commercial or financial relationships that could be construed as a potential conflict of interest.

Copyright (c) 2019 Succo and Crosetti. This is an open-access article distributed under the terms of the Creative Commons Attribution License (CC BY). The use, distribution or reproduction in other forums is permitted, provided the original author(s) and the copyright owner(s) are credited and that the original publication in this journal is cited, in accordance with accepted academic practice. No use, distribution or reproduction is permitted which does not comply with these terms. 